\title{
MASCULINIDADE E CIÚME NA PERSPECTIVA DA TEORIA DA SEDUÇÃO GENERALIZADA
}

Paulo Carvalho Ribeiro*

\begin{abstract}
RESUMO. Partindo das contribuições freudianas sobre as relações do ciúme com a projeção e a homossexualidade, propõe-se no presente artigo uma retomada do papel do masoquismo primário e da identificação feminina como elementos definidores do ciúme masculino patológico. As condições originárias de constituição do psiquismo, vistas sob o ângulo da Teoria da Sedução Generalizada, proposta por Jean Laplanche, são relacionadas tanto ao masoquismo primário quanto à identificação feminina. A situação assimétrica entre o adulto, portador de uma sexualidade inconsciente, e a criança, destituída de recursos psíquicos para lidar com as mensagens sexuais do adulto, caracteriza, segundo esse autor, a situação antropológica fundamental.
\end{abstract}

Palavras-chave: Ciúme; masculinidade; masoquismo.

\section{MASCULINITY AND JEALOUSY ACCORDING TO THE THEORY OF GENERALIZED SEDUCTION}

\begin{abstract}
Taking Freud's ideas on the relation between jealousy, projection and homosexuality as a starting point, this article focuses on the role played by primary masochism and feminine identification in the formation of masculine pathological jealousy. The early conditions of psychic constitution, as seen by the Theory of Generalized Seduction, are linked to primary masochism and feminine identification alike. According to that author, the asymmetric situation between the adult - whose unconscious sexuality is fully developed - and the child - still lacking psychic capacity to deal with the sexual messages coming from the adult - characterizes the fundamental anthropological situation.
\end{abstract}

Key words: Jealousy; masculinity; masochism.

\section{MASCULINIDAD Y CELOS DESDE LA PERSPECTIVA DE LA TEORÍA DE LA SEDUCCÍON GENERALIZADA}

RESUMEN. Partiendo de las contribuciones de Freud sobre las relaciones de los celos con la proyección y la homosexualidad, se propone en este artículo la reanudación de la función del masoquismo primario y de la identificación femenina como elementos definidores de los celos masculinos patológicos. Las condiciones originarias de la constitución del psiquismo, vistas desde el ángulo de la Teoría de la Seducción Generalizada propuesta por Jean Laplanche, están relacionadas tanto al masoquismo primario como a la identificación femenina. La situación asimétrica entre el adulto, que tiene una sexualidad inconsciente, y el niño, carente de recursos psíquicos para lidiar con los mensajes sexuales del adulto, caracteriza, según este autor, la situación antropológica fundamental.

Palabras-clave: Celos; masculinidad; masoquismo.

\footnotetext{
Doutor em Psicanálise e Psicopatologia pela Universidade Paris 7, com pós-doutorado em Psicologia Clínica na PUC-SP.
} Professor associado da Universidade Federal de Minas Gerais. 
No primeiro parágrafo de seu texto, sobre alguns mecanismos neuróticos no ciúme, na paranoia e na homossexualidade, Freud (1922/2011) parte da aproximação do ciúme com o luto, no que se refere ao caráter frequentemente normal desses dois estados afetivos, para logo em seguida distinguir três estágios do ciúme, a saber, o competitivo ou normal, o projetado e o delirante. Na descrição do ciúme normal, encontramos um breve relato das fantasias de um homem ciumento cujo teor impressiona por sintetizar o que nos parece essencial a ser considerado quando se aborda o ciúme masculino na perspectiva do sofrimento psíquico. A importância desse relato justifica sua transcrição na íntegra:

Sei também de um homem que sofria enormes ataques de ciúme e que, segundo seu próprio relato, sentia tormentos atrozes ao se pôr conscientemente no lugar da mulher infiel. A sensação de completo desamparo que então experimentava, as imagens com que descrevia seu estado - abandonado à sanha do abutre, como Prometeu, ou lançado a um ninho de cobras amarrado -, ele próprio ligava às impressões deixadas por alguns ataques homossexuais, quando era menino. (Freud, 1922/2011, p. 211)

Dificilmente encontraríamos uma aproximação mais nítida entre o ciúme e a situação de desamparo, característica dos primeiros meses de vida do bebê humano. Não se trata aqui, obviamente, da simples incapacidade de sobreviver com os parcos recursos fisiológicos e motores desse período inicial, mas de uma dimensão do desamparo que nos permite falar de uma situação antropológica fundamental (Laplanche, 2007), definida como situação de passividade do bebê perante a sexualidade inconsciente do adulto e os efeitos traumáticos de uma inevitável sedução decorrente dessa situação. Deixamos, portanto, claro desde já que abordaremos o tema do sofrimento psíquico causado pelo ciúme na perspectiva da teoria da sedução generalizada de Jean Laplanche.

\section{CIÚME E MASOQUISMO PRIMÁRIO}

Entre os vários caminhos que poderíamos tomar nessa empreitada de relacionar o sofrimento advindo do ciúme com a sedução originária, a via do masoquismo primário se impõe pelos motivos que apresentaremos em seguida, e que, na verdade, já se encontram muito bem indicados pelo caráter masoquista das fantasias do homem ciumento, relatadas por Freud na passagem citada acima. Comecemos, então, pela apresentação dos argumentos que justificam a aproximação entre sedução originária e masoquismo primário.

Seguindo alguns marcos estabelecidos por Laplanche (1992) em seu texto sobre masoquismo, podemos afirmar que a sedução originária cria as condições para que o masoquismo se constitua como posição libidinal originária. Entre os fatores que contribuem para isso, destacamos os seguintes como sendo os principais: a passividade da criança perante a implantação de mensagens comprometidas pela sexualidade consciente e inconsciente do adulto, o caráter invasivo de todas essas mensagens, a prioridade do registro corporal na implantação das mesmas e a invariável conexão dessas mensagens com a fantasia.

Sobre o caráter invasivo das mensagens, é preciso insistir no fato de que qualquer invasão pressupõe um limite a ser transposto, logo algo como uma delimitação do eu deve responder pela existência desse limite sob forma de representação psíquica. Mas, a armadilha paradoxal da sedução situa-se precisamente na antecedência da invasão relativamente à existência do limite a ser invadido, ou seja, o eu. Quando ele é criado, ele delimita automaticamente um corpo que já foi invadido e que passa assim a conter elementos internos atacantes.

A prioridade do registro corporal na situação de sedução originária advém, em última instância, do fato de que a manipulação do corpo é a condição fundamental da sobrevivência do bebê, e essa manipulação se dá tanto no sentido do holding (Winnicott, 1988) quanto no sentido da intrusão, o que quer dizer que mesmo as manipulações mais ternas e delicadas podem adquirir a posteriori o caráter de invasão. Em outras palavras, podemos afirmar, seguindo Jacques André (1995), que originariamente o corpo do bebê é uma superfície exposta à invasão e à imposição de sensações.

Tomando agora o caráter invasivo da sedução e sua relação com as fronteiras corporais, torna-se claro que a fantasia induzida na criança pela mensagem sexual do adulto deverá guardar alguma relação com esses fatores. Quando Laplanche toma como exemplo típico do efeito da sedução originária a fantasia clássica cujo enunciado é bate-se numa criança ou "meu pai bate no meu irmãozinho ou irmãzinha" (Freud, 1919/1969e, p. 227), além da intenção de mostrar a efetividade da mensagem como apelo à tradução, podemos também constatar a nítida referência ao inevitável ataque às fronteiras corporais inerente à sedução. A fantasia masoquista revela-se assim como uma consequência incontornável da natureza invasiva das mensagens sexuais do adulto.

Em sua leitura do texto "O problema econômico do masoquismo" (Freud, 1924/2007), sob a ótica da 
sedução generalizada, Laplanche (1992) identifica um extravio do pensamento de Freud semelhante ao que pode ser observado nos desdobramentos da teoria da sedução, desde de sua formulação inicial, tal como apresentada nos "Estudos sobre a histeria" (Freud \& Breuer, 1969/1893-95) e na correspondência com Fliess. A teoria freudiana do masoquismo também se extravia ao adotar um ponto de vista endogênico e biologizante, sendo a explicação metapsicológica fundada na oposição entre pulsão de morte e pulsão de vida, a principal responsável por esse extravio.

Segundo Freud (1924/2007), o masoquismo seria o resultado do tratamento erótico (pulsão de vida) sofrido pelos resíduos internos da pulsão de morte. $\mathrm{O}$ masoquismo erógeno, sendo visto por Freud como estritamente corporal no sentido de uma busca do orgasmo pela dor, é tomado como evidência do tratamento libidinal da pulsão de morte. A fantasia masoquista, componente essencial do masoquismo, fica assim restringida ao masoquismo feminino e é entendida como secundária ao elemento tanático endógeno, ao passo que o masoquismo moral passa a ser visto como o estágio final, dessexualizado, em que o ego sofre a punição do superego.

Surpreendentemente, nesse mesmo texto de 1924, Freud (1924/2007) fala de uma sobreposição do infantil, do passivo e do feminino no masoquismo e embora prometa explicá-la, não o faz. Como bem aponta Laplanche (1992), essa sobreposição contraria a tese canônica do caráter masculino da sexualidade precoce em ambos os sexos e se constitui como uma pista da existência de outra corrente de explicação teórica da qual Freud teria se extraviado.

Outro ponto a ser destacado é a retomada no "Problema econômico do masoquismo" (Freud, 1924/2007) da teoria da coexcitação formulada nos "Três ensaios sobre a teoria sexual" (Freud, 1905/1969): "É bem possível que nada de considerável importância ocorra no organismo sem contribuir com algum componente para a excitação sexual" (p. 240). Duas concepções de coexcitação são possíveis. Se a ênfase é colocada nas funções autoconservativas, temos uma concepção endogênica da coexcitação. Mas se a ênfase é colocada no aporte do outro, temos uma concepção alteritária da coexcitação. Laplanche (1992) deixa claro que no lugar da pulsão de morte é preciso recolocar a invasão sedutora do outro, conferindo à teoria da coexcitação seu lugar na sedução originária.

Ainda em "O problema econômico do masoquismo", Freud (1924/2007) faz uma incessante confusão entre desprazer e dor, esquecendo-se de sua clássica teoria da dor, que estabelece o rompimento de um limite como seu princípio fundamental. Superando a oposição simples em que aumento de excitação = desprazer e diminuição de excitação = prazer, Freud reafirma o eventual caráter prazeroso do aumento de excitação, cujo protótipo é a excitação sexual.

Ora, para Laplanche (1992), não se trata de pensar o masoquismo como desprazer $=$ prazer, mas sim como dor $=$ prazer, ou seja, efração dos limites corporais/egoicos $=$ excitação $=$ prazer. Dessa forma, $a$ teoria da coexcitação, na medida em que sustenta a existência de uma excitação oriunda do outro, estabelece os fundamentos metapsicológicos da sedução originária e a coloca em relação direta com o masoquismo primário. O problema econômico do masoquismo se resolve, portanto, com a introdução de um elemento não-econômico, ou seja, a mensagem do outro e seu poder de recolocar a fantasia na origem da sexualidade. Enfim, podemos afirmar com Laplanche que a fantasia masoquista se apresenta como a expressão libidinal de uma conjunção originária entre a invasão pelo outro e a excitação sexual.

\section{CIÚME E HOMOSSEXUALIDADE MASCULINA}

Retomando agora o texto sobre ciúme, paranoia e homossexualidade (Freud, 1922/2011b), focalizaremos primeiramente as teses freudianas sobre a gênese da homossexualidade, para em seguida abordarmos a paranoia, antes de voltarmos ao ciúme. As considerações que acabamos de fazer sobre masoquismo e sedução originária nos ajudarão a fundamentar a leitura crítica das teses freudianas e a proposição de nossas próprias ideias sobre esses temas.

A relação da homossexualidade com o ciúme é inegável, pelo menos no caso do ciúme masculino delirante. Mas quando consideramos a teoria freudiana sobre a gênese da homossexualidade masculina e sua relação com a teoria sobre a gênese do ciúme delirante, a grande questão que se apresenta, a nosso ver, se refere à compatibilidade dessas duas teorias. De forma bem precisa e direta, nossa questão pode ser formulada nos seguintes termos: as teses de Freud sobre a homossexualidade masculina facilitam ou dificultam a compreensão do ciúme delirante?

Muitas das ideias apresentadas nos textos sobre Leonardo (Freud, 1910/1969b) e Schreber (Freud, 1911/1969c) são retomadas nesse artigo de 1922 (Freud, 1922/2011b). Três teses constituem os pilares da compreensão freudiana sobre a homossexualidade masculina: 1) Ao final da puberdade, o adolescente, intensamente ligado libidinalmente à mãe, transforma essa ligação objetal em identificação e passa a ter como objetos amorosos jovens como ele próprio, para que possa amá-los como sua mãe o amou. A extraordinária fixação libidinal à mãe contribui 
decisivamente para a dificuldade em substituí-la por outros objetos femininos, de tal forma que a identificação a ela pode ser entendida como uma estratégia para manter a fidelidade ao primeiro objeto de amor. 2) Existe, entre os homossexuais masculinos, uma tendência à escolha narcísica de objeto, supostamente mais "próxima (...) e mais facilmente realizável do que o direcionamento para o outro sexo" (Freud, 1922/2011b, p. 221). 3) A importância do complexo de castração é determinante nesses casos, pois reforça a escolha narcísica ao estabelecer como condição de investimento libidinal a presença do órgão masculino no objeto, além de determinar uma estratégia de fuga da rivalidade e da eventual retaliação paterna por meio da renúncia ao objeto heterossexual.

A esses três motivos explicativos da homossexualidade masculina, já presentes em seu pensamento, desde 1910 pelo menos, Freud (1922/2011b) acrescenta um quarto motivo que nos interessa, particularmente, na medida em que se refere à sedução:

\footnotetext{
Apego à mãe - narcisismo - medo da castração: esses fatores (de modo algum específicos, aliás) encontramos até aqui na etiologia psíquica da homossexualidade, e a eles se agregam também a influência da sedução, que causa uma fixação prematura da libido, e do fator orgânico, que favorece o papel pacífico na vida amorosa. (Freud, $1922 / 2011$ b, p. 222)
}

É bem possível que Freud tenha acrescentado esse quarto motivo a partir da consideração do caso do "Homem dos lobos" (Freud, 1918/1969d), no qual a sedução precoce pela irmã e uma alegada preponderância orgânica da libido anal teriam contribuído para a corrente homossexual de seu paciente russo. Além disso, é válido lembrar que a fantasia de outro paciente de Freud, transcrita no início deste artigo, cujo ciúme da mulher o conduzia a colocar-se no lugar dela e a imaginar-se numa posição passiva e masoquista, foi associada pelo próprio paciente aos ataques homossexuais sofridos quando ele ainda era menino.

Mas o que de fato nos interessa nesse quarto motivo é a inclusão de um fator alteritário na explicação da homossexualidade masculina. Diferentemente da fixação à mãe e do narcisismo fálico, que aparecem como fatores que poderíamos denominar de inatos, a sedução vem reintroduzir a força determinante do outro, tanto nos mecanismos de identificação como na escolha objetal.

De fato, a naturalidade com que Freud estabelece que a mãe é o primeiro objeto de investimento libidinal por parte do menino traz todas as evidências de sua crença na força que a determinação biológica exerceria nessa escolha. Embora não tenhamos a intenção de retomar aqui todas as críticas à atribuição de uma força semelhante ao instinto, capaz de assegurar o desejo sexual do menino pela mãe, nem tampouco pretendemos retomar as objeções à atribuição de um valor narcísico inato ao órgão masculino, é imprescindível apontar para a relação desse viés teórico com uma concepção da identificação na qual o investimento libidinal do objeto é nitidamente separado dos processos identificatórios.

Em "Psicologia das massas e análise do eu" (Freud, 1921/2011a), essa distinção é levada às últimas consequências, quando Freud estabelece, para o menino, uma identificação primária ao pai de préhistória do complexo de Édipo, concomitante e inteiramente distinta do investimento libidinal da mãe. Separar identificação de investimento libidinal atende à necessidade de proteger a suposta masculinidade primária do menino contra a possibilidade de uma feminilidade primária resultante da identificação também primária com a mãe.

Sobre essa identificação primária, é fundamental esclarecer que não se trata apenas, e nem principalmente, de um tipo de assimilação dos modos de ser da mãe, tomada como representante do gênero feminino, à semelhança do que propõe Robert Stoller (1975) ao falar do imprinting da feminilidade a partir do contato excessivamente próximo e constante dos meninos altamente afeminados, por ele estudados, com suas mães. Seguindo uma via aberta por Jacques André (1995), consideramos a situação de exposição dos bebês humanos à penetração generalizada, inerente à sedução originária, o fator decisivo na constituição da identificação feminina primária. As origens femininas da sexualidade confundem-se com o processo de tradução/simbolização das vivências de passividade e suscetibilidade à intrusão, anteriores ao surgimento das instâncias psíquicas, logo anteriores à existência do eu nos bebês (cf. Ribeiro, 2007; Ribeiro, Carvalho, Ribeiro, Lucero \& Araújo, 2011).

\section{IDENTIFICAÇÃO FEMININA E CIÚME}

Existe, portanto, a possibilidade de explicação teórica da homossexualidade masculina baseada no recalque de uma identificação feminina primária indissociável dos efeitos traumáticos da sedução originária. Algumas moções pulsionais homossexuais nos homens, quer permaneçam inconscientes, quer se tornem manifestas, guardam uma relação com a posição seduzida e passiva originária, inteiramente 
convergente com a posição masoquista originária tal como a descrevemos a partir da teoria da sedução generalizada.

Todos esses elementos teóricos até aqui reunidos nos permitem agora retomar a relação entre homossexualidade masculina, paranoia e ciúme delirante na perspectiva da identificação feminina primária recalcada. Ao adotarmos essa via, o principal ganho que pode ser auferido relativamente à explicação freudiana é a vinculação direta dessas duas manifestações patológicas aos elementos recalcados mais significativos em termos da constituição psíquica. A compreensão dos mecanismos envolvidos em uma perturbação psicopatológica de tamanha monta, como é o caso da paranoia, parece-nos requerer conceitos que nos aproximem mais das origens do psiquismo do que o conceito de projeção conjugado às transformações gramaticais da proposição intolerável "eu (um homem) o amo" (Freud, 1911/1969c, p. 6).

Em que pese a clara relação da projeção com o recalcado, afirmada por Freud (1911/1969c) na análise das memórias de Schreber e reafirmada enfaticamente no texto de 1922, a convicção de que o conteúdo recalcado nesses casos se refere exclusivamente a uma "homossexualidade desandada" (einer vergorenen Homossexualität) (Freud, 1922/2011b, p. 213) restringe muito o alcance da explicação freudiana, sobretudo quando nos lembramos que a origem da homossexualidade masculina é vista por Freud como um processo eminentemente edípico, que se manifesta na adolescência, e resulta, em última instância, do excessivo apego libidinal à mãe e do excessivo valor narcísico conferido ao órgão masculino. Ora, essas são posições subjetivas que nos distanciam muito da passividade e da condição invadida das origens do psiquismo, em que acreditamos ser mais pertinente buscar os elementos mais fundamentais dos mecanismos psicopatológicos determinantes da paranoia.

Basta que nos atentemos para alguns aspectos proeminentes da paranoia e do ciúme delirante para vislumbrarmos a relação desses fenômenos com moções pulsionais enraizadas nas origens passivas e masoquistas da constituição psíquica. Fazendo abstração da controvertida diferenciação entre esquizofrenia paranoide e paranoia, podemos tomar o emblemático caso Schreber como evidência inquestionável da condição submissa na qual se encontra o psicótico perante as formações delirantes e alucinatórias que o dominam. A presença de convicções delirantes e vivências alucinatórias relacionadas a todo tipo de invasão, abuso, transformação e manipulação do corpo não é uma característica específica das manifestações psicopatológicas de Schreber. Elas são a norma nos quadros de psicoses delirantes crônicas, da mesma forma que o caráter feminilizante dessas vivências é atestado por um número impressionante de pacientes homens.

Focalizando agora os homens acometidos de delírios celotípicos, a busca incessante e obstinada pelos detalhes mais ínfimos e íntimos das supostas cenas de traição não deixa margem para que se duvide da identificação inconsciente do ciumento com a mulher supostamente infiel. O testemunho do paciente de Freud, que se imaginava no lugar da mulher adúltera e, ao fazê-lo, dava vazão às suas próprias fantasias de passividade e submissão ao abuso invasivo e penetrante do outro, está longe de ser uma exceção.

Para citar apenas mais um exemplo disso, nada melhor do que uma pequena amostra dos depoimentos de Simon, um dos casos de ciúme patológico estudados por Daniel Lagache (1947/1986) e detalhadamente relatados em seu clássico livro sobre o ciúme amoroso. A seguinte passagem nos informa sobre seu gosto e interesse pela revelação, por parte de sua amante, dos detalhes de suas relações com outros homens.

\begin{abstract}
Simon não parece propenso ao ciúme retrospectivo. Sua parceira chegou a lhe fazer confidências de extrema precisão sobre sua vida passada, que nos levam a vê-la sob a dupla perspectiva da lubricidade e da infidelidade; ela as apresenta a ele como confissões que aliviam sua consciência, nisso encontrando, talvez, mais uma excitação e um prazer do que um conforto moral. Quanto mais Simon participa da intimidade de sua amante e quanto mais seu desejo de conhecer todos os pensamentos dela obtém satisfação, mais ele entra no jogo. (Lagache, 1947/1986, p. 437, tradução nossa).
\end{abstract}

Paralelamente ao gosto pela revelação das experiências sexuais pregressas e atuais de sua amante com outros homens, Simon admite sua identificação com ela e o efeito de compreensão e aceitação que isso lhe assegura.

Eu me esforço para me colocar no lugar dela,
para imaginar que eu sou ela. Eu entendo
melhor como ela me ama, eu sei que ela
pensa frequentemente em mim, eu
compreendo que ela não é como eu a imagino
tão frequentemente, à espreita de qualquer
ocasião [para traí-lo]. (Lagache, 1947/1986,
p. 536).

Cotejando agora os dois casos, o do paciente de Freud e o de Simon, temos duas vertentes quase 
opostas de identificação com a mulher supostamente infiel. No primeiro caso trata-se de uma identificação na qual se acentuam as manifestações fantasmáticas das moções pulsionais mais intoleráveis e recalcadas; ao passo que no segundo caso o homem ciumento tenta se apaziguar por meio da identificação, atribuindo características à amante que se opõem ou pelo menos amenizam o poder perturbador das fantasias que ele próprio cria sobre o caráter incontrolável e devasso do comportamento sexual dela. Seja com o propósito se aproximar-se subjetivamente da posição passiva e masoquista primária, seja procurando dela se distanciar, a identificação do ciumento paranoico com a mulher infiel sempre se manifesta, evidenciando assim a sobreposição daquilo que Freud tanto insistiu em manter separado, a saber, investimento objetal e identificação.

Essas evidências da importância da identificação no ciúme nos levam a considerar algumas particularidades da projeção, classicamente associada a este fenômeno. A nosso ver, a ideia de que o homem ciumento projeta em sua parceira a infidelidade que ele mesmo pratica ou deseja realizar preserva uma identidade masculina mesmo nos casos em que se trata de um desejo homossexual projetado. De fato, se a transformação da frase "eu (um homem) o amo" em "ela o ama" fosse apenas uma projeção, nada permitiria supor que a identidade masculina do sujeito da primeira frase estaria em questão.

O caráter delirante tantas vezes adquirido pelo ciúme e sua associação com as psicoses requerem explicações que contemplem outros fenômenos presentes nessas psicopatologias delirantes crônicas. No caso de homens psicóticos delirantes crônicos, o empuxo à mulher, tal como Lacan (1973/2001) nomeou os fenômenos delirantes e alucinatórios de feminilização, dificilmente poderia ser explicado pela projeção apenas.

Tomando, mais uma vez, o caso Schreber como exemplo, a ideia de uma homossexualidade projetada mostra-se inteiramente insuficiente ao constatar que não se tratava, de forma alguma, de um impulso a se colocar como homem em relação ao outro homem, mas de um imperativo de se transformar em uma mulher a ser penetrada pelos raios divinos e assim conceber uma nova categoria de seres humanos. Nesse caso, a transformação da asserção "eu (um homem) $o$ amo" em "eu não o amo, eu o odeio (porque ele me persegue)" deixa de lado a característica mais marcante da perseguição, que poderia ser assim enunciada: "ele quer me transformar em mulher".

Feitas essas considerações, podemos formular a hipótese de que o ciúme patológico dos homens, além de contar com o mecanismo de projeção, baseia-se também na identificação. Imaginar a cena de infidelidade e ter a convicção de sua realidade é uma forma de atualizar e ao mesmo tempo desconhecer a identificação com a mulher infiel. Nesse sentido, querer controlar cada passo e cada pensamento da amante, esposa ou parceira é uma tentativa desesperada de conter uma exigência pulsional que se realiza na própria obstinação com o controle, visto que ele é indissociável do desejo de que a infidelidade seja um fato. Não é propriamente a esposa ou a amante que trai o ciumento delirante; ele na verdade é traído por uma identificação que não pode ser reconhecida e que dele exige uma realização de desejo tão interditada quanto à infidelidade.

Os excessos pulsionais do homem ao imaginar a cena de adultério, quase invariavelmente nela incluindo a degradação da mulher e a presença de elementos sadomasoquistas, vêm revelar as raízes do ciúme patológico na situação originária de passividade da criança perante o "abuso" sexual inconscientemente cometido pelo adulto na sedução originária. A convergência do infantil, do feminino e do passivo, surpreendentemente afirmada e não explicada por Freud (1924/2007) em "O problema econômico do masoquismo", encontra assim no ciúme patológico dos homens um de seus locais de plena realização.

Seria um engano supor que essa dimensão identificatória do ciúme se restringe aos casos patológicos. Ao associarmos o ciúme dos homens às condições originárias em que se dá a constituição psíquica, estamos na verdade tratando de fenômenos cuja amplitude ultrapassa largamente o campo das patologias psíquicas. Somos, assim, conduzidos a uma conclusão sobre a sexualidade masculina em geral e queremos explicitá-la por meio de uma breve consideração a respeito da hipótese de Silvia Bleichmar sobre esse tema.

Em seu livro intitulado "Pardojas de la sexualidad masculina" (Bleichmar, 2007), a psicanalista argentina, após um longo percurso teórico entremeado por relatos de atendimentos clínicos por ela realizados e de estudos antropológicos realizados por outros autores, formula a seguinte hipótese:

\footnotetext{
Afirmei a hipótese de que a identificação masculina em termos de sexo (não de gênero) se constitui pela introjeção fantasmática do pênis paterno, quer dizer, pela incorporação anal de um objeto privilegiado que se articula ao sujeito submetendo sua sexualidade masculina a um atravessamento, paradoxalmente, feminino. Nesse sentido, assim como é impossível o posicionamento feminino sem passar pelo atravessamento fálico, a masculinidade seria impensável sem brindar-se fantasmaticamente com uma
} 
iniciação por meio da qual outro homem brinda o menino com as condições da masculinidade (Bleichmar, 2007, p. 235-236, tradução nossa).

Essa mesma hipótese é reafirmada por ela ao comentar o ponto de vista de Bernard Sergent (1986), cujo livro que trata da homossexualidade na mitologia grega tornou-se uma referência fundamental sobre o tema. Silvia Bleichmar (2007) considera limitada a afirmação de Sergent, segundo a qual os homens, da mesma forma que falam línguas diferentes e se casam seguindo procedimentos variados, escolheriam, em cada cultura, seu modo de viver e exercer sua sexualidade. Para ela, essa conclusão

\begin{abstract}
(...) perde de vista um fato central: a iniciação à sexualidade sob um modo passivo, feminino, de recepção do pênis de um homem por parte de outro homem, é um ritual de acesso à masculinidade cujas formas simbólicas podem ter modos diversos, mas que confirma nossa hipótese sobre a complexidade da masculinidade como um caminho que atravessa inevitavelmente a feminilidade. (Bleichmar, 2007, p. 238-239)
\end{abstract}

Silvia Bleichmar não abre mão, portanto, do caráter universal da passagem pela posição feminina perante um homem como via de acesso à masculinidade.

De nossa parte, consideramos fundamental ampliar ainda mais o alcance dessa hipótese afirmando, na esteira de Jean Laplanche (1992) e Jacques André (1995), a origem necessariamente passiva e masoquista da sexualidade em geral, tanto masculina quanto feminina. Em que pese os diferentes destinos dessas marcas originárias nos indivíduos que se reconhecem como pertencentes ao gênero masculino ou feminino, e até mesmo naqueles que pretendem escapar dessa bipartição supostamente ideológica, permanece o fato de que a sexualidade infantil recalcada em todos os seres humanos contraria frontalmente a virilidade calcada na potência ativa, dominadora e penetrante que alimenta imaginariamente todo narcisismo fálico.

Não se trata, portanto, a nosso ver, de uma masculinidade cujo fundamento universal e paradoxal é a incorporação anal do pênis paterno, como quer Bleichmar, mas da masculinidade fundamentalmente assentada na paradoxal negação de uma feminilidade que a sustenta. Em outras palavras, para que um homem se excite sexualmente e seja capaz de penetrar alguém de forma viril e ativa é preciso que ele possa negociar consigo mesmo sua identificação com a pessoa penetrada e apassivada. O ciúme do homem é, invariavelmente, uma tentativa de realizar essa negociação.

O homem que precisa ter ciúmes, tão bem retratado no famoso conto sobre esse tema, de Menotti Del Picchia (1964), é muito mais a norma do que a exceção, na medida em que nenhum homem escapa dessa negociação. Quando ela fracassa, as consequências podem se estender desde um simples episódio de impotência psicogênica até o mais grave delírio celotípico e aos desfechos trágicos, como em Otelo, em que o ciumento é levado ao assassinato da mulher amada e ao subsequente suicídio. Porém, diferentemente da trama shakespeariana, o ciumento delirante sempre designa a si mesmo o vil papel de Iago.

\section{REFERÊNCIAS}

André, J. (1995). Aux origines féminines de la sexualité. Paris: PUF.

Bleichmar, S. (2007) Paradojas de la sexualidade masculina. Buenos Aires: Paidós.

Del Picchia, M. (1964). "O homem que precisava ter ciúmes", In J. Penteado (Org.), Primores do conto universal(pp. 193-202), São Paulo: Edigraf.

Freud, S (1969e). Uma criança é espancada, In J. Strachey (Ed. e J. Salomão, Trad.), Edição Standart Brasileira das obras psicológicas completas de Sigmund Freud. (Vol. 17, pp. 223-256). Rio de Janeiro: Imago. (Original publicado em 1919).

Freud, S. \& Breuer, J. (1969). Estudos sobre Histeria, In J. Strachey (Ed. e J. Salomão, Trad.), Edição Standart Brasileira das obras psicológicas completas de Sigmund Freud. (Vol. 2, pp. 13-364). Rio de Janeiro: Imago. (Original publicado em 1893-95).

Freud, S. (1969a). Três ensaios sobre a teoria da sexualidade, In J. Strachey (Ed. e J. Salomão, Trad.), Edição Standart Brasileira das obras psicológicas completas de Sigmund Freud. (Vol. 7, pp. 123-238). Rio de Janeiro: Imago. (Original publicado em 1905).

Freud, S. (1969c). Notas psicanalíticas sobre um relato autobiográfico de um caso de paranoia, In J. Strachey (Ed. e J. Salomão, Trad.), Edição Standart Brasileira das obras psicológicas completas de Sigmund Freud. (Vol. 12, pp. 15-111). Rio de Janeiro: Imago. (Original publicado em 1911).

Freud, S. (1969d). Historia de uma neurose infantil, In J. Strachey (Ed. e J. Salomão, Trad.), Edição Standart Brasileira das obras psicológicas completas de Sigmund Freud. (Vol. 17, pp. 13-156). Rio de Janeiro: Imago. (Original publicado em 1918).

Freud, S. (2007) O problema econômico de masoquismo, In (Luiz Hanns, Trad.), Obras Psicológicas de Sigmund Freud. (Vol. 3, pp. 103-124). Rio de Janeiro: Imago. (Original publicado em 1924).

Freud, S. (2010). Introdução ao narcisismo, In (Paulo César de Souza, Trad.), Obras Completas. (Vol. 12, pp. 
13-50). São Paulo: Companhia das Letras. (Original publicado em 1914).

Freud, S. (2011a). Psicologia das massas e análise do eu, In (Paulo César de Souza, Trad.), Obras Completas. (Vol. 15, pp. 13-113). São Paulo: Companhia das Letras. (Original publicado em 1921).

Freud, S. (2011b) Sobre alguns mecanismos neuróticos no ciúme, na paranoia e na homossexualidade, In (Paulo César de Souza, Trad.), Obras Completas. (Vol. 15, pp. 209-224). São Paulo: Companhia das Letras. (Original publicado em 1922).

Freud, S.(1969b). Leonardo da Vinci e uma lembrança de sua infância, In J. Strachey (Ed. e J. Salomão, Trad.), Edição Standart Brasileira das obras psicológicas completas de Sigmund Freud. (Vol. 11, pp. 53-124). Rio de Janeiro: Imago. (Original publicado em 1910).

Lacan, J. (1973/2001). O aturdito. In Outros escritos (pp. 448-497). Rio de Janeiro: Jorge Zahar Editor.

Lagache, D. (1986/1947). La jalousie amoureuse, Paris: PUF.

Laplanche, J. (1992). La position originaire du masochisme dans le champ de la pulsion sexuelle, In La révolution coperniciènne inachevée. Paris: Aubier.
Laplanche, J. (2007). À partir de la situation anthropologique fondamentale, In Sexual, la sexualité élargie au sens freudien. Paris: PUF

Ribeiro, P. C. (2007). Identification passive, genre et séduction originaire. Psychiatrie Française, 38(4), 2148.

Ribeiro, P. C., Carvalho, M. T. M., Ribeiro, L. M. C, Lucero, A., \& Araújo, C. G. (2011). Imitação: seu lugar na psicanálise. São Paulo: Casa do Psicólogo.

Sergent, B. (1986). Homosexuality in Greek myth, Boston: Beacon Press.

Stoller, R.J. (1975). The transexual experiment. London: Hogarth Press.

Winnicott, D. W. (1988). Human Nature. Londres: Free Association Books.

Recebido em 19-07-2012

Aceito em 27-11-2012
Endereço para correspondência:
Paulo Carvalho Ribeiro. Rua Bambuí 25/1600, cep 30210-490, Serra, Belo Horizonte-MG, Brasil.E-mail: icaro.bhz@terra.com.br. 